\title{
Automated breast ultrasound system (ABUS): can it replace mammography as a screening tool?
}

\author{
Yasser I. Abd Elkhalek ${ }^{1,2^{*}}$, Ahmed M. Bassiouny ${ }^{1}$ and Rasha Wessam Abdel Rahman Abdel Hamid ${ }^{3}$
}

\begin{abstract}
Background: Mammography is the most accepted, accurate, and effective modality in screening of breast cancer, yet its sensitivity is affected by the density of the breast tissue. Alternative methods for screening are the sonography and MRI but both had their limitations. A new option named ABUS (automated breast ultrasound system) is now proposed to overcome the breast US limitation as it is time-consuming and operator-dependent and to overcome the costly time-consuming MRI. The objectives of the study are to evaluate the accuracy of ABUS in the detection of different breast lesions as a substitution for mammography. This prospective study included 25 women outreached for digital mammography or handheld ultrasound examination at the period between January 2017 and February 2018. Women have no specific age group.
\end{abstract}

Results: Significant improvement in the detection of breast lesions by ABUS use with mammogram especially in dense breasts (ACR class C and D)

Conclusion: ABUS is a promising competitor to mammogram in screening of breast lesions

Keywords: Thin-film transistors, Terminal ductal lobular unit, Triple negative, Ultrasound

\section{Background}

The mammogram is now used in a large scale in screening of breast lesions, and it proved to be effective in the detection of the lesions and so reducing mortality from breast cancer. Exposure to radiation is a major disadvantage of mammogram and recent studies showed about a $43 \%$ reduction in screening programs for fear of radiation. Moreover, its sensitivity in lesion detection is much lower in dense breasts. Some studies show low sensitivity down to $50 \%$ or less as dense breasts can obscure the tumors and make reading and interpreting the exam difficult and inaccurate. This resulted in increased false-positive lesions and increased number of useless biopsies and so increased costs and increased the patient's anxiety. About $50 \%$ of young females less than 50 years of age have dense breasts and about $1 / 3$ of older females more than 50 years also have dense breasts.

\footnotetext{
* Correspondence: yasserib77@gmail.com

${ }^{1}$ Radiodiagnosis Department, Ain Shams University, Cairo, Egypt

${ }^{2}$ Nasr City, Egypt

Full list of author information is available at the end of the article
}

Other screening tools include breast ultra-sonography and breast MRI. Sonography is a low-cost tool for screening and is widely available than MRI, yet it is operator-dependent, time-consuming, and nonreproducible especially in large breasts. ABUS is a new tool to overcome such disadvantages [1].

Both handheld ultrasound (HHUS) and ABUS have very high sensitivity (100\% for both) and high specificity (85.0\% and $95.0 \%$, respectively). Moreover, ABUS showed a higher diagnostic accuracy (97.1\%) than handheld ultrasound (91.4\%) for breast neoplasms [2].

ABUS is like the traditional ultrasound using highfrequency sound waves passing and reflected from the breast tissues, but it gives a 3D volume image of the whole breast at once. This is more useful for females with dense breasts as they give better data and allow the radiologists to use different angles and planes for examination and so a better interpretation of the lesions. It also takes much less time than HHUS. ABUS transducer automatically scans both breasts and so operator dependency is much lower than HHUS [3] 


\section{Aim of the work}

The aim of this study to evaluate the ABUS machine as non-X-ray hazardous tool in early detection of different breast lesion.

\section{Methods}

All 25 women underwent breast screening. A supplementary sonography study was performed to all cases with positive findings in mammography. No exclusion criteria. The institution review board approved the study. Written consent was taken from the patients with detailed steps of the procedure.

All patients were submitted to the following: demographic and clinical data collection, including patient's name, age, and marital status; duration of illness; past history; family history; and provisional diagnosis.

Mammography was performed using a GE Healthcare device with dual-energy acquisitions CEDM "Senographe 2000 D full field digital mammography Essential GE Healthcare." A full-field system using a detector with flat panel and Csl absorber was used with field size of $19 \times$ 23 and pitch of $100 \mathrm{~mm}$ with image matrix $=1914 \times$ 2294.

\section{Technique of digital mammography}

Standard views medio-lateral-oblique and cranio-cauda1 views were taken for all patients.

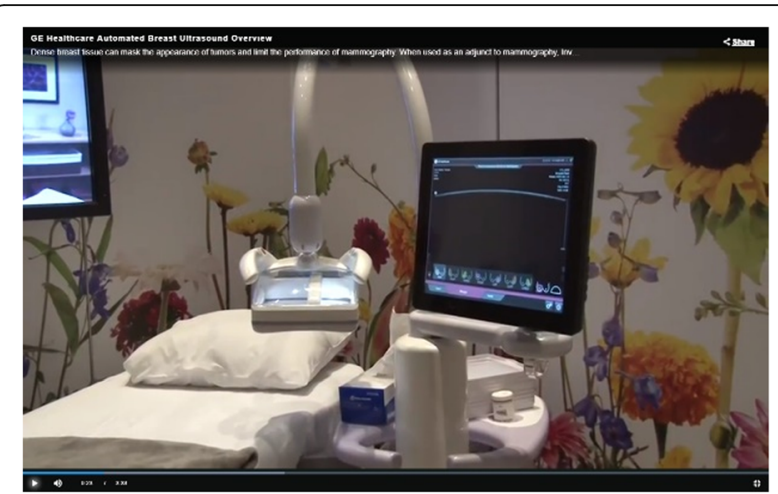

Fig. 1 ABUS machine used to perform our cases

ABUS examination was performed using a GE Healthcare ultrasound device allowing ultrasound waves transmission by high-frequency probe $(7-13 \mathrm{MHz})$ passing through the breast tissues with software- and hardwarespecific adaptations for image acquisition and processing (Fig. 1).

\section{Technique of ABUS}

The patient lies in supine position. A machine arm that is computer-guided acquired the images through the attached transducer. The images are acquired in rows in a longitudinal manner as well as transverse images. Antero-posterior (AP), lateral, and medial standard
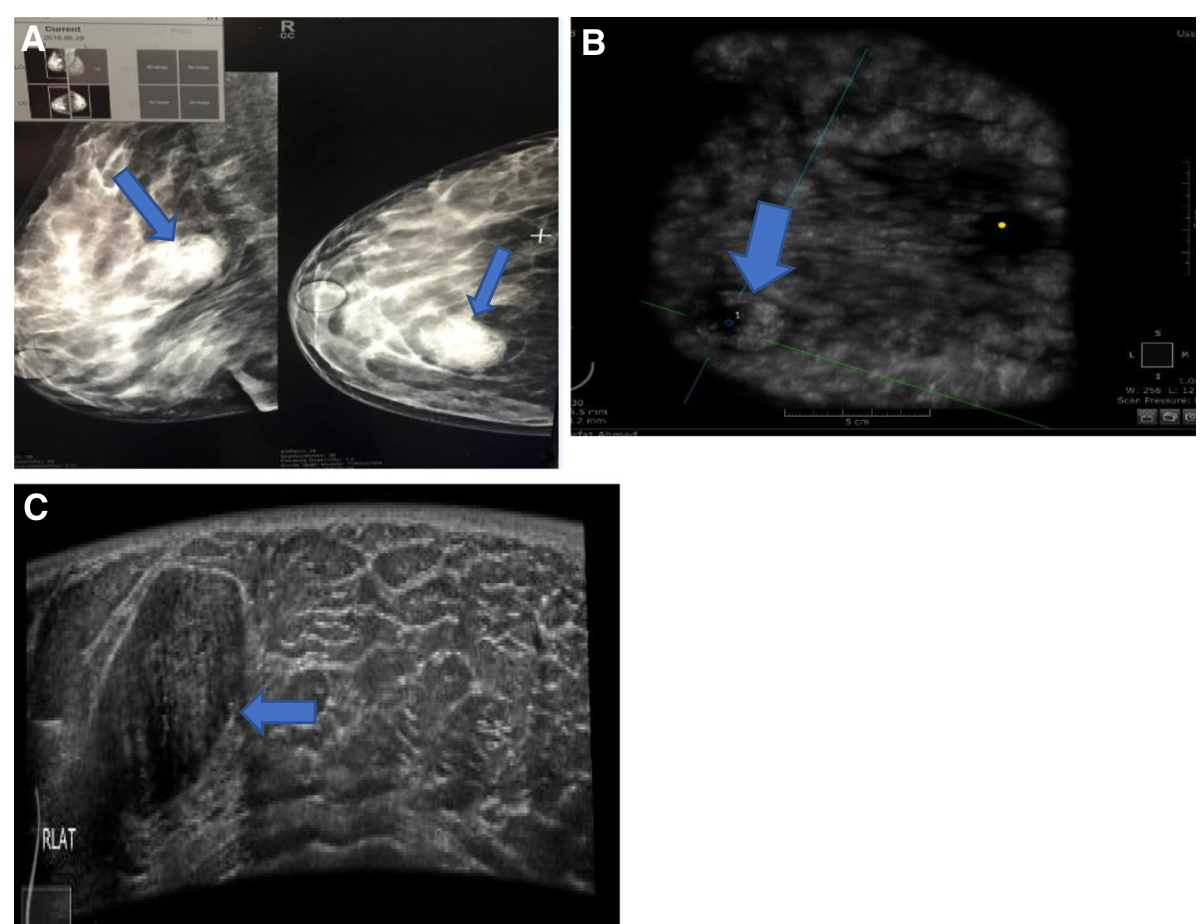

Fig. 2 a Mammogram shows an ovoid opacity at right breast $10^{\prime}$ clock position. b, c Lesions proved by ABUS to be a solid ovoid lesion typical for fibroadenoma 
Table 1 Age of the patients

\begin{tabular}{lc}
\hline Age of the patients & No. of the patients (25) \\
\hline Mean \pm SD & $43.40 \pm 9.08$ \\
Range & $29-69$ \\
$<40$ years & $11(44.0 \%)$ \\
$\geq 40$ years & $14(56.0 \%)$ \\
\hline
\end{tabular}

Table 3 Detected lesions by mammogram and correlated BIRADS

\begin{tabular}{lll}
\hline Lesions & & No. of the patients (25) \\
\hline Mammogram & Negative & $8(32.0 \%)$ \\
Mammogram BIRADS & Positive & $17(68.0 \%)$ \\
& 1 & $8(32.0 \%)$ \\
& 2 & $7(28.0 \%)$ \\
& 3 & $3(12.0 \%)$ \\
& 4 & $4(16.0 \%)$ \\
& 5 & $3(12.0 \%)$ \\
& Mean \pm SD & $2.48 \pm 1.42$ \\
\hline
\end{tabular}

Table 2 ACR density of the breast

\begin{tabular}{lll}
\hline ACR density of the breast & No. of the patients & $\%$ \\
\hline A & 4 & 16.0 \\
B & 8 & 32.0 \\
C & 9 & 36.0 \\
D & 4 & 16.0 \\
\hline
\end{tabular}

Table 4 Detected lesions by ABUS and correlated BIRADS

\begin{tabular}{lll}
\hline Lesions & & No. of the patients (25) \\
\hline ABUS & Negative & $5(20.0 \%)$ \\
& Positive & $20(80.0 \%)$ \\
ABUS BIRADS & 1 & $5(20.0 \%)$ \\
& 2 & $8(32.0 \%)$ \\
& 3 & $5(20.0 \%)$ \\
& 4 & $4(16.0 \%)$ \\
& 5 & $3(12.0 \%)$ \\
& Mean \pm SD & $2.68 \pm 1.31$ \\
\hline
\end{tabular}


Table 5 Comparison between detected lesions and correlated BIRADS by mammogram and ABUS

\begin{tabular}{|c|c|c|c|c|c|c|}
\hline & & Mammogram & $A B \cup S$ & Test & $P$ & Sig. \\
\hline & & No. $=25$ & No. $=25$ & & & \\
\hline Lesion & Negative & $8(32.0 \%)$ & $5(20.0 \%)$ & 0.936 & 0.333 & NS \\
\hline & Positive & 17 (68.0\%) & 20 (80.0\%) & & & \\
\hline BIRADS & Mean \pm SD & $2.48 \pm 1.42$ & $2.68 \pm 1.31$ & -1.732 & 0.096 & NS \\
\hline & Range & $1-5$ & $1-5$ & & & \\
\hline & 1 & $8(32.0 \%)$ & $5(20.0 \%)$ & -1.259 & 0.868 & NS \\
\hline & 2 & 7 (28.0\%) & $8(32.0 \%)$ & & & \\
\hline & 3 & $3(12.0 \%)$ & $5(20.0 \%)$ & & & \\
\hline & 4 & $4(16.0 \%)$ & $4(16.0 \%)$ & & & \\
\hline & 5 & $3(12.0 \%)$ & $3(12.0 \%)$ & & & \\
\hline
\end{tabular}

NS non-significant, $S$ significant, $H S$ highly significant

$P$ value $>0.05$ non-significant

$P$ value $<0.05$ significant

$P$ value $<0.01$ highly significant

views were taken for each breast (Fig. 2). There is ability to add some additional views in some cases as views for axillary tail and special upper quadrants localized views.

\section{Statistical analysis}

Analysis of data was done by IBM computer using SPSS (Statistical Program for Social Science version 12). Description of quantitative variables was mean and range. Description of qualitative variables was number and percentage. Chi-square test of independence is used to determine if there is a significant relationship between the variables. Independent $t$ test is used for separate groups of variables.

\section{Results}

Twenty-five female patients, age ranging 29-69 years (Tables 1 and 2) having their routine screening or complaining from breast pain or a palpable mass were submitted to ABUS and mammography.

In our study, ABUS system was applied on 25 patients of mean age 43.4 with standard deviation of \pm 9.08 . Eleven patients were below 40 years and 14 patients above 40 years. Thirteen patients $(52 \%)$ with dense breasts were ACR C and D (9 and 4, respectively), while 12 patients (48\%) were ACR A and B (4 and 8, respectively).

The percentage of BIRAD II and BIRAD III (Figs. 2 and 4) detected lesions in mammogram was $28 \%$ and $12 \%$, while, in ABUS, it increased to $32 \%$ and $20 \%$, respectively (Tables 3 and 4); thus, ABUS is a useful tool in detection of benign lesions and probably benign lesions compared to mammogram (Tables 5 and 6). On the other hand, we noticed no significant difference at BIRAD IV and V (between the two studies as we show in the tables) (Fig. 3).

The sensitivity of the ABUS is about $100 \%$, and that means, in all the results of the mammogram study, ABUS can detect it without significant change, while the specificity of the ABUS was about $62 \%$ and was more evident in benign lesions (Table 7).

We found that the detected lesions by ABUS in the age group below 40 years was more than the mammogram (ABUS $=7$ cases and mammogram $=5$ cases) (Table 8 ), while in the age group above 40 years the ABUS found 1 case only more than the mammogram study (Tables 9 and 10) .

Table 6 Comparison between detected positive and negative lesions by mammogram and ABUS

\begin{tabular}{|c|c|c|c|c|c|c|c|c|}
\hline & & \multicolumn{2}{|c|}{ Negative mammogram } & \multicolumn{2}{|c|}{ Positive mammogram } & \multirow{2}{*}{$\begin{array}{l}\text { Test } \\
\text { value }\end{array}$} & \multirow{2}{*}{$\begin{array}{l}P \\
\text { value }\end{array}$} & \multirow[t]{2}{*}{ Sig. } \\
\hline & & No. & $\%$ & No. & $\%$ & & & \\
\hline \multirow[t]{2}{*}{ ABUS } & Negative & 5 & 62.5 & 0 & 0.0 & 13.281 & 0.000 & HS \\
\hline & Positive & 3 & 37.5 & 17 & 100.0 & & & \\
\hline
\end{tabular}

NS non-significant, $S$ significant, $H S$ highly significant

$P$ value $>0.05$ non-significant

$P$ value $<0.05$ significant

$P$ value $<0.01$ highly significant 


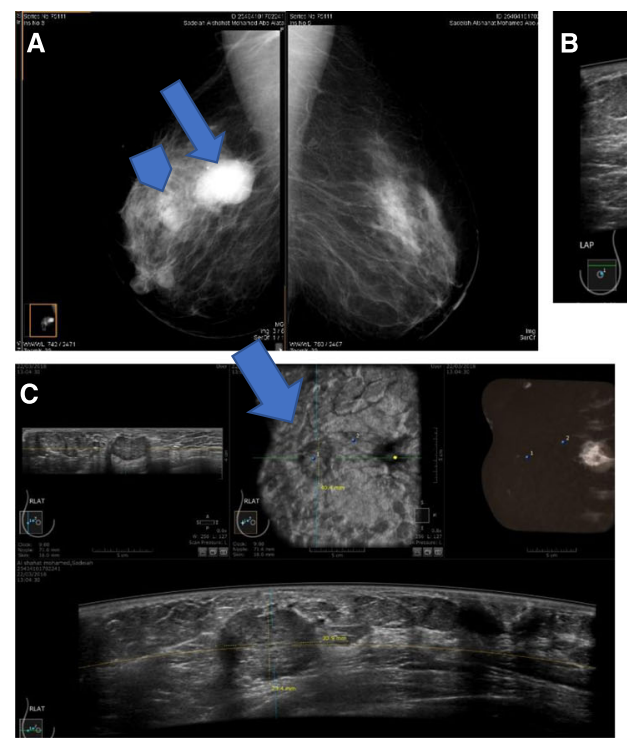

Fig. 3 a Left mammogram shows two lesions, one well defined at 12 o'clock (arrow) and the other is ill-defined opacity at 1 o'clock (arrow head). b, $\mathbf{c}$ Lesions proved by ABUS in different planes with 3D image to be a solid ovoid lesion typical for fibroadenoma (arrow) and the other is a malignant-looking mass lesion (arrow head BIRADS IVc)

\section{Discussion}

Breast cancer is now considered one of the main causes of death of females above 40 years and one of the main causes of health problems in females [4].

Many breast lesions are either asymptomatic or mildly symptomatic and so early discovery of breast lesions by screening is important to undergo management strategies that are less invasive for better outcome results [5].

Till the time being, mammography is still the best screening method as it is the best studied and accurate tool for general population screening, yet this accuracy drops in cases with dense breasts [5].

Breast density in mammography is a strong predictor of development of breast cancer and this is well established. The denser the breast tissue, the higher the risk of cancer development [6].

ABUS is a system that is a computer-based automated system that performs and records entire breast ultrasound. The physician then can review the images on a workstation with reconstruction capabilities that allow viewing the breast tissue and lesions in different angles and planes and in 3D models.

ABUS has a standard protocol for images acquisition that requires short training by the medical personnel performing it without the presence of the experienced radiologists in contrast to the HHUS. 3D ABUS eliminates the operator-dependent factor and enables reproducibility. It also eliminates nonstandardized documentation [7].
The automatic screening and imaging presets settings for entire breast volume are optimized according to breast size. Breast size is categorized from $\mathrm{A}$ to $\mathrm{D}+$ where $\mathrm{A}$ is the smallest and $\mathrm{D}+$ is the largest. The automated machine then sends the entire set of images to a workstation [8].

The ABUS system dedicated software "computed aided detection (CAD) software" improves the rates of detection of breast masses by radiologist as proved by van zelst et al. [9]. They found better sensitivity for all readers by about $5.2-10.6 \%$ by CAD software [9]

It is also a time saver for about 20-30 min compared to HHUS as stated by Brem et al. [10].

Moon et al. also proved the increased accuracy to discriminate the benign from malignant lesion through CAD software [11].

The use of shear wave elastography was proved to improve the accuracy of categorization of breast lesions either benign or malignant. On the ABUS machine, elastography capabilities can be added and it is still under research [12].

Both mammography and ABUS were similar in detection of the suspicious and malignant lesions categorized as BIRADS 4 and 5 (4 patients with BIRADS 4 (16\%) and 3 with BIRADS 5 (12\%)). Eight cases reported normal by mammography but only 3 by ABUS. The difference was in the BIRADS 2 and 3 lesions where ABUS detected 3 more lesions than the mammogram; one of them was of BIRADS 2 category and 2 of them were BIRADS 3 (Figs. 2, 3, and 4) 
Table 7 Comparison of accuracy measures of ABUS and mammogram than ratio of sensitivity and specificity

\begin{tabular}{llllll}
\hline & Sensitivity & Specificity & + PV & - PV & Accuracy \\
\hline ABUS & $100.0 \%$ & $62.5 \%$ & $85.0 \%$ & $100.0 \%$ & $88.0 \%$ \\
Mammogram & $85 \%$ & $100 \%$ & $100 \%$ & $72.7 \%$ & $89 \%$ \\
\hline
\end{tabular}

Table 8 ACR

\begin{tabular}{|c|c|c|c|c|c|c|c|}
\hline \multirow[t]{2}{*}{$A C R$} & \multicolumn{2}{|c|}{$<40$ years } & \multicolumn{2}{|c|}{$\geq 40$ years } & \multirow{2}{*}{$\begin{array}{l}\text { Test } \\
\text { value }\end{array}$} & \multirow{2}{*}{$\begin{array}{l}P \\
\text { value }\end{array}$} & \multirow[t]{2}{*}{ Sig. } \\
\hline & No. & $\%$ & No. & $\%$ & & & \\
\hline$A$ & 2 & 18.2 & 2 & 14.3 & 5.328 & 0.149 & NS \\
\hline B & 1 & 9.1 & 7 & 50.0 & & & \\
\hline C & 5 & 45.5 & 4 & 28.6 & & & \\
\hline$D$ & 3 & 27.3 & 1 & 7.1 & & & \\
\hline
\end{tabular}

NS non-significant, $S$ significant, $H S$ highly significant

$P$ value $>0.05$ non-significant

$P$ value $<0.05$ significant

$P$ value $<0.01$ highly significant

Table 9 Comparison between detected lesions and correlated BIRADS by mammogram with patient's ages

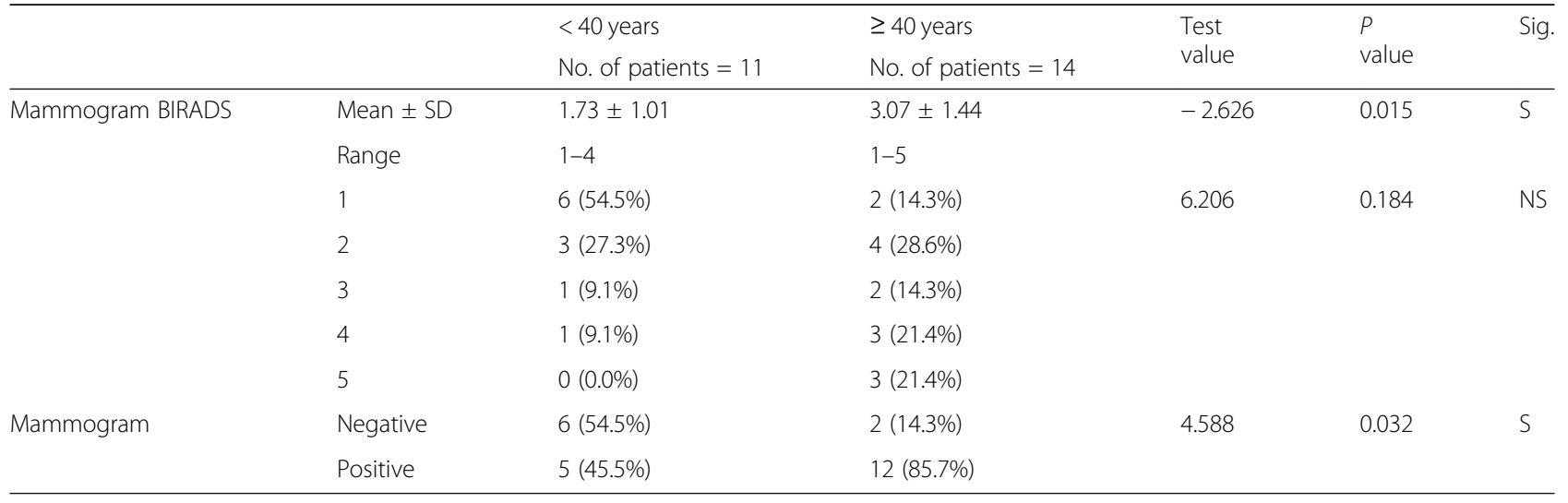

NS non-significant, $S$ significant, $H S$ highly significant

$P$ value $>0.05$ non-significant

$P$ value $<0.05$ significant

$P$ value $<0.01$ highly significant

Table 10 Comparison between detected lesions and correlated BIRADS by ABUS with patient's ages

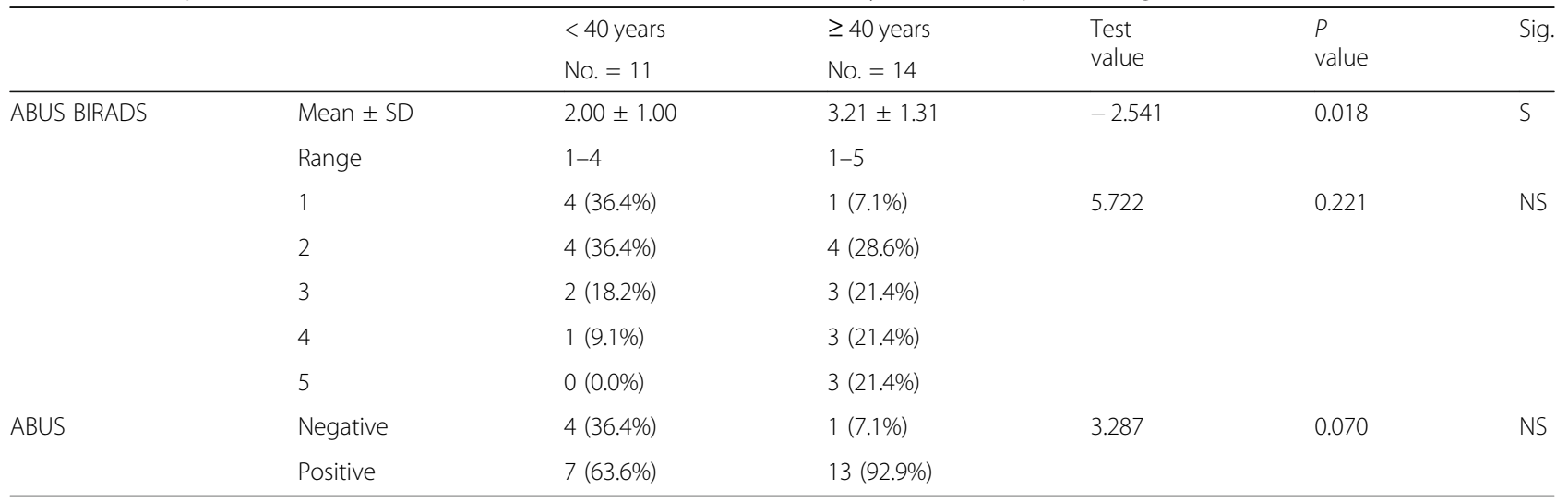

NS non-significant, $S$ significant, $H S$ highly significant

$P$ value $>0.05$ non-significant

$P$ value $<0.05$ significant

$P$ value $<0.01$ highly significant 

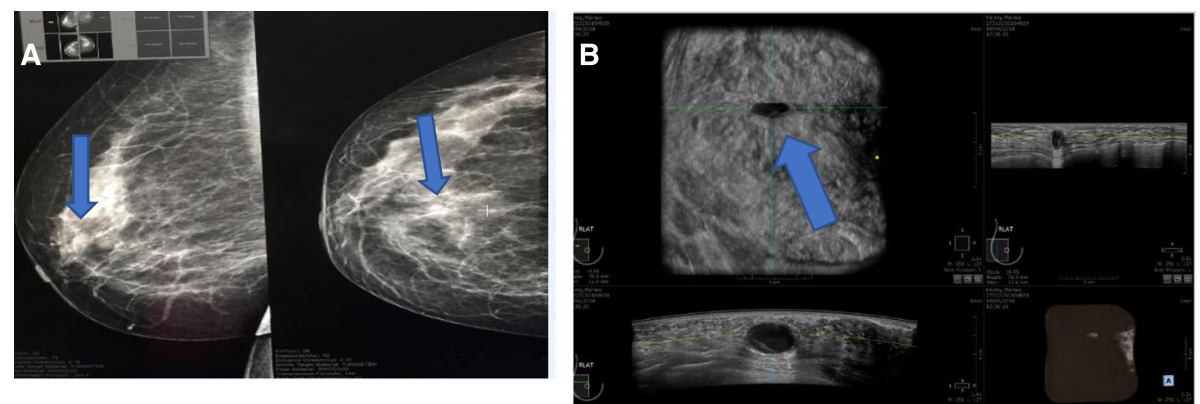

Fig. 4 a Mammogram shows a small dense lesion medio-lateral (left) and craniocaudal (right). b Lesion proved by ABUS with 3D image to be a cyst at 12 o'clock in axial and coronal scans

The comparison between the detected lesions and the BIRADS correlation by mammogram and ABUS found a highly significant correlation, $P$ value $=0$. The ABUS sensitivity was $100 \%$, specificity $62.5 \%$, and $88 \%$ accuracy.

\section{Conclusion}

ABUS has advantages of better diagnostic accuracy of breast lesions in terms of early detection, better categorization, and accurate assessment. It is operatorindependent, less time-consuming, and allows entire breast scanning with no ionizing radiation and it has no contraindication unlike mammography. ABUS with mammography together will add more value in the breast lesions diagnostic field.

\section{Abbreviations}

ABUS: Automated breast ultrasound system; AP: Antero-posterior;

CAD: Computer-aided detection; HHUS: Handheld ultrasound; MRI: Magnetic resonance imaging; SPSS: Statistical Program for Social Sciences

\section{Acknowledgements}

Not applicable

\section{Authors' contributions}

Both $\mathrm{YI}$ and $\mathrm{AB}$ participated in collecting data and images, manuscript revision, and sequence alignment; drafted the manuscript; participated in the design of the study; and performed the statistical analysis. RW participated in collecting data and images of most of the cases included. All authors read and approved the final manuscript.

\section{Funding}

No funding sources

\section{Availability of data and materials}

The datasets used and/or analyzed during the current study are available from the corresponding author on reasonable request.

\section{Ethics approval and consent to participate}

This study was approved by the Research Ethics Committee of the Faculty of Medicine at Ain Shams University in Egypt on 2016 (no reference number was given at that time). All patients included in this study gave written informed consent to participate in this research. If the patient was unconscious at the time of the study, written informed consent for their participation was given by their parent or legal guardian. No patients were less than the age of 16.

\section{Consent for publication}

All patients included in this research gave written informed consent to publish the data contained within this study. If the patient was unconscious when consent for publication was requested, written informed consent for the publication of this data was given by their parent or legal guardian. No patients were less than the age of 16 .

\section{Competing interests}

The authors declare that they have no competing interests.

\section{Author details}

${ }^{1}$ Radiodiagnosis Department, Ain Shams University, Cairo, Egypt. ${ }^{2}$ Nasr City, Egypt. ${ }^{3}$ Radiodiagnosis Department, Kaser el Aini University, Cairo, Egypt.

Received: 13 June 2019 Accepted: 16 September 2019

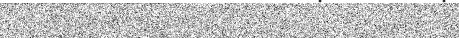

\section{References}

1. Kim HH, Cha JH (2015) Current status of automated breast ultrasonography. Ultrasonography 34(3):165-172

2. Xi L, Jianwei $W$, Feng $H$ (2012) Analysis of eighty-one cases with breast lesions using automated breast volume scanner and comparison with handheld ultrasound. Eur J Radiol 81(5):873-878

3. Jacob JMD (2012) Dense breast tissue: supplemental screening. Imag Technol News 11:46-49

4. Yang T, Liang H, Chouc C, Huang J, Pan H (2013) Adjunctive digital breast tomosynthesis in diagnosis of breast cancer. Biomed Res 2013: 597253

5. Devolli-Disha E, Manxhuka-Kërliu S, Ymeri H, Kutllovci A (2009) Comparative accuracy of mammography and ultrasound in women with breast symptoms according to age and breast density. Bosn J Basic Med Sci. 9(2): $131-136$

6. Sleeba T, Subapradha A, Ramachandran M, Krishnaswami M (2013) Role of dual-energy contrast-enhanced digital mammography as a problemsolving tool in dense breasts: a case report. Indian J Radiol Imaging 23(3):219

7. Berg A (2003) Mammography screening: are women really giving informed consent? (Counterpoint). J Nat Cancer Inst 95(20):1511-1512

8. Wang H, Jianga Y, Zhua Q, Zhanga J, Daia Q, Liua H, Lai X, Sunb Q (2012) Differentiation of benign and malignant breast lesions: a comparison between automatically generated breast volume scans and handheld ultrasound examinations. Eur J Radiol 81:3190-3200

9. van Zelst JCM, Tan T, Platel B, de Jong M, Steenbakkers A, Mourits M, Grivegnee A, Borelli C, Karssemeijer N, Mann RM (2017) Improved cancer detection in automated breast ultrasound by radiologists using computer aided detection. Eur J Radiol 89:54-59

10. Brem RF, Rapelyea JA, Torrente J et al (2012) Interpretation time of 3D automated breast ultrasound. Presented at: The American Roentgen Ray Society 2012 Annual Meeting, Vancouver 
11. Moon WK, Shen Y, Huang C, Chiang L, Chang R (2011) Computer-aided diagnosis for the classification of breast masses in automated ultrasound images. Ultrasound Med. Biol. 37(4):539-548

12. Lee SH, Chang JM, Kim WH et al (2012) Differentiation of benign from malignant solid breast masses: comparison of two-dimensional and threedimensional shear-wave elastography. Eur Radiol. https://doi.org/10.1007/ s00330-012-2686-9 (Epub ahead of print)

\section{Publisher's Note}

Springer Nature remains neutral with regard to jurisdictional claims in published maps and institutional affiliations.

Submit your manuscript to a SpringerOpen ${ }^{\mathcal{O}}$ journal and benefit from:

- Convenient online submission

Rigorous peer review

- Open access: articles freely available online

- High visibility within the field

- Retaining the copyright to your article

Submit your next manuscript at $\boldsymbol{\nabla}$ springeropen.com 